\title{
DIE BOODSKAP VAN NICEA
}

\author{
PROF. DR. F. J. VAN ZYL
}

Op 20 Mei, 1650 jaar gelede, is 'n plekkie met die naam van Nicea op die wêreldkaart geplaas en is hierdie naam onuitwisbaar geskrywe in die geskiedenis van die kerk. Uit hierdie plekkie, klein onder die stede van die destydse wêreld, klein soos die eertydse Betlehem onder die stede van Juda, het daar iets gekom wat van beslissende betekenis gewees het vir die geloof en die belydenis van die kerk, omdat dit iets wesenliks verwoord het van Hom wat ook uit 'n vergete plekkie gekom het waarvan niemand verwag het dat daar iets goeds uit kan kom nie. En terwyl dit in hierdie voordrag om die boodskap van Nicea gaan, is dit miskien goed om heel aan die begin die aandag te vestig op 'n tersydse troosboodskap van Nicea vir alle veragtes en geringes en onaansienlikes, of hulle nou mense of kerke is. Hy wat uit Nasaret gekom het, om wie dit in Nicea gegaan het, het ook 'n donkie nodig gehad. Hy kan ook van eenvoudiges en geringes gebruik maak om Hom en die evangelie in die wêreld te dien.

Nicea is vir ons belangrik omdat daar in hom 'n kerkvergadering plaasgevind het. As ons die boodskap van Nicea wil verneem, is dit nodig dat ons noukeurig aandag gee aan alles wat op daardie byeenkoms plaasgevind het, sowel as aan sy voorgeskiedenis en nageskiedenis. Behalwe vir die geloofsbelydenis wat op hierdie vergadering geformuleer is, is die konsilie van Nicea om twee ander redes van besondere betekenis. In die eerste plek was dit die eerste ekumeniese sinode in die geskiedenis van die kerk. Oor die werklike getal afgevaardigdes na die konsilie is daar nie eenstemmigheid nie. Gewoonlik word 'n simboliese getal 318 genoem, na aanleiding van die geoefende manne in die huis van Abraham wat uitgetrek het om Lot te bevry (Gen. 14:14). Waarskynlik was daar net 255:1) 5 uit die westerse, en 250 uit die oosterse deel van die ry. Daar was biskoppe uit Europa, Afrika en Asië, Siriërs, Fenisiërs, Arabiere, Egiptenare, Tebane; mense uit Pontus, Galasië, Kappadosië, Frigië en Pamfilië. Teenoor mekaar staande groepe, ja selfs skeurmakers is uitgenooi. Uit hierdie groot diversiteit van opvattings het daar 'n formulering van die Bybelse waarheid gekom wat deur al die eeue heen sy skoonheid en aktualiteit behou het. As uit hierdie feit 'n boodskap geformuleer moet word, kan dit die beste gedoen word in die woorde van $\mathrm{H}$. Echternach - vertaal deur J. F. van Os uit „Kirchenväter, Ketzer und Konzilien“ - „Het concilie van Nicea . . is een indrukwekkend bewys hoe God zijn plannen volvoert dwars door het leven van de handelende personen heen, dwars door hun

1) Helmut Echternach, KERKVADERS KETTERS EN CONCILIES, Amsterdam, 1965, bl. 110. 
bedoelingen en hun ideeën, dwars door hun belijden en hun falen, hun inzichten en hun dwalingen. Het laat zien, hoe in de kerkgeschiedenis elke misvatting ten slotte moet dienen om tot een dieper verstaan te komen van wat in de Heilige Schrift is geopenbaard. Het laat tevens zien, dat aan de kerk op deze wereld nooit rust beschoren is. Waar de waarheid vertikaal in dit aardse vlak inslaat, daar beeft de aarde, daar is grote beroering. Maar te midden daarvan heerst er vrede, die niet verstoord kan worden" (bl. 102).

Dit is wel so dat die woord ekumenies, as gevolg van die optrede van die Wêreldraad van Kerke, vir ons vandag aanduiding is van ' $n$ swaarbelaste saak en dat die ekumeniese aandele in ons eie kerk nie hoog genoteer word nie. Tog is dit iets groots as gelowiges in Pretoria, in Moskou en Alexandrië, in Canterbury en Hamburg, in New York en in Buenos Aires gebind word deur dieselfde belydenis. ' $n$ Mens sal die boodskap van Nicea seker nie reg en volledig hoor as jy nie ook die oproep tot aandag vir die ekumene verneem nie. Nóg vir die teologiese arbeid, nóg vir die kerklike lewe kan dit op die duur gesond wees vir 'n kerk as hy te lank afgeslote en vereensaam op hom self gerig bestaan. Hy moet hom noodwendig al meer met al minder besig hou en al minder met wat wesenlik nodig is.

Die ander rede waarom die konsilie van Nicea besondere betekenis het, is omdat die inisiatief tot hierdie vergadering nie van die kerk af uitgegaan het nie. maar van die keiser. ' $n$ Mens kan jou beswaarlik indink in die gemoedstemming van die manne wat na soveel vervolging deur vyandige keisers op 20 Mei 325 in die paleis van Konstantyn die Grote kon saamkom vir die openingsitting van hulle kerkvergadering waar die keiser self die leiding geneem het. Die groot wending het gekom toe Konstantyn en Licinius in die edik van Milaan, ${ }^{2}$ ) 313 n.C., dit as hulle oortuiging uitgespreek het dat hulle van alle dinge wat nodig is vir die voordeel van die mens, die diens van God voor alles stel. Daarom moet elkeen die reg hê om die godsdiens wat hy kies ongehinderd te beoefen, en word daardie vryheid ook aan die christene gegun. In die geskiedenis van kerk en sending word die jaar 313 n.C. dan ook as 'n betekenisvolle keerpunt aangestip. Vir baie swaar geteisterde christene was dit 'n ongekende weelde om uit die katakombes te kom en die son van vryheid te geniet in die ryk van die goedgesinde keiser. Dit het verreikende gevolge gehad, nie net vir die uiterlike omstandighede van die kerk nie, maar ook vir sy innerlike gesteldheid. Tot in daardie tyd het die kerk hoofsaaklik bestaan uit eenvoud:ge en nederige mense, slawe, vrouens, kleinhandelaars en enkele soldate. Hulle was nie baie wyses na die vlees nie, nie baie magtiges, nie baie edeles

2) Henry Bettenson, (Selected and Edited) DOCUMENTS OF THE CHRISTIAN CHURCH, London 1946, bl. 22. 
nie. As 'n mens 'n duidelike beeld van die kerk van daardie tyd wil kry, moet jy luister na wat die heiden Celcus van Alexandrieë van hulle gesê het: ${ }^{3}$ ) „, . . hulle doel is om alleen waardelose, veragtelike mense, sotte, slawe, arm vroue en kinders te oortuig. Hulle gedra hulle soos kwakke en bedelaars en sal dit nooit waag om 'n gehoor van intelligente mense toe te spreek nie... ons sien wolkammers, skoenmakers, wasvrouens, mense van die uiterste onkunde en gebrek aan opvoeding en geleerdheid. Hulle is versigtig om hulle monde nie oop te maak in die teenwoordigheid van hulle base nie wat volwasse is en in staat om self te oordeel. Maar as hulle kinders alleen kan kry. of vrouens net so onnosel soos hulle self, dan begin hulle met hulle wonderverhale. Dis alleen sulkes wat hulle kan verander in gelowiges..."

Hoewel daar vir oordrywing toegelaat moet word, sal 'n mens aan die ander kant ook moet erken dat 'n groot deel seker waar is wat Celcus hier sê. Met die wending wat daar deur die gunstige houding van Konstantyn gekom het, het die uiterlike omstandighede van die kerk radikaal verander. En toe die christendom later as ryksgodsdiens begunstig is, is hy bedreig deur die geweldige toestroming. In 'n kort tydjie het hy vervierdubbel. Dit het mode geword om christen te wees. En soos dit met die meeste modes gaan, geskied navolging gewoonlik sonder innerlike oortuiging, met die gevolg dat vervlakking intree. Met die toestroming van die groot getalle het die wêreld in die kerk gekom, wat natuurlik baie gevare meebring as dit nie 'n bekeerde wêreld is nie.

Gelukkig is die prent nie so donker as wat hy geskilder is nie. Daar is ook ' $n$ ligkant. Dit is wel waar dat die kerk uit eenvoudiges en geringes bestaan het, en tog het hy in hierdie eerste jare ook 'n merkwaardige kwota aan intelektueles en goedgeleerdes opgelewer, soos Klemens, Origenes, Tertullianus, Chrysostomos e.a.

Nie net het hierdie manne goed vertoon teenoor die enkele groot geeste uit die Griekse wêreld van daardie tyd nie, maar hulle aanwesigheid is ' $n$ aanduiding van wat daar op teologiese gebied te wagte kon wees. Dit is eers in hierdie tyd dat 'n mens teologie in die werklike sin kry, toe die ontmoeting van die evangelie met die Griekse denke plaasgevind het. Die teologiese situasie wat Konstantyn gevind het in die westelike deel van die kerk rondom 313 , was maar baie verwarrend. Dit was 'n tyd van baie vergissings en dwalings op teologiese gebied. Dit was veral die Donatistiese stryd oor die ketterdoop wat die gemoedere warm gemaak het. Konstantyn het hom onmiddellik hiermee begin bemoei en pogings aangewend tot beslegting van die stryd. Dit het uitgeloop op die sinode van Arles in 314 waar die stryd besleg is met die bepaling dat elke doop erken word as dit bedien is in die naam van die Drie-Enige God en

3) Stephen Neil, A HISTORY OF CHRISTIAN MISSIONS, 1964, bl. 45. 
as aan die dopeling die regte geloofsbelydenis geleer is. Hierdie bepaling is later op die konsilie van Nicea goedgekeur.

Toe Konstantyn in 324 heerser van die hele ryk word, ook van die oostelike gedeelte, en ook deur die christene van die ooste met groot vreugde begroet is, vind hy egter daar net soos in die westelike gedeelte van die ryk 'n kerkstryd. Die vraag waarom dit in hierdie stryd gegaan het, was die verhouding van die Seun, van Christus, tot die Vader. Brandpunt van die stryd was Alexandrië waar die presbiter Arius in botsing gekom het met sy biskop Alexander. Aanvanklik het die keiser die Ariaanse stryd nie erger beskou as 'n getwis onder teoloë nie en tot vrede gemaan, egter sonder sukses. Lateraan het hy sy ou raadgewer. Ossius van Corduba, gestuur om bemiddelend op te tree. Hy het egter gou uitgevind dat dit hier om ernstiger en dieper vraagstukke gaan as wat dit op die oog af lyk. Dit was waarskynlik op sy advies dat die keiser die konsilie van Nicea saamgeroep het.

Voordat ons daartoe oorgaan om die wesenlike saak waarom dit op die konsilie gegaan het, nader te betrag, is dit miskien hier die beste plek om die aandeel wat die keiser in die hele aangeleentheid gehad het, effens krities te beskou. Georg Kretschmar sê in sy artikel „Die Konzile der Alten Kirche" (49v.) dat Nicea 'n keiserlike sinode was. Konstantyn het hom saamgeroep en gefinansier, hom bygewoon en as't ware fakties gelei, self voorstelle gemaak wat ook aanvaar is en by die kerklike anathema ook nog strawwe van die kant van die staat gevoeg. Kretschmar gaan verder deur te sê dat Konstantyn seif sy hele handeling teruggevoer het na 'n goddelike inspirasie. Bekend is natuurlik ook die verhaal van die sg. visioen tydens sy opmars na Rome toe 'n ligtende kruis in 'n wolk gesien is met die randskrif: toutō nikā. ,Konstantyn het geglo dat hy deur die God van die christene verkies is en gelei word en daarom het hy die kerk as die plek van diens aan hierdie God as werktuig gekies vir die vernuwing van sy ryk." ${ }^{\prime 4}$ ) Die gevaar van die beskouing van Konstantyn is onteenseglik daarin geleë dat hy die kerk slegs gesien het as werktuig in diens van die staat, en dat die kerk die plek van die ou Romeinse staatsgodsdiens ingeneem het as waarborg van die welsyn van die staat. Nicea het wat dit betref ook vir ons vandag 'n boodskap, 'n waarskuwende boodskap, want dis nie net Konstantyn wat die kerk in die diens van allerlei menslike groothede sien i.p.v. in diens van God alleen nie. Laat ons maar gewaarsku wees teen die oordrewe beklemtoning van die belangrikheid van die kerk vir die behoud van nasionalisme, blankedom en so meer, Die inisiatief wat Konstantyn geneem het tot saamroeping van die konsilie, het vir die kerk ook nog 'n ander boodskap nl. dat onrus in die kerk nie bevorderlik is vir die openbare lewe in die

4) Georg Kretschmar, DIE ÖKUMENISCHE KONZILE DER CHRISTENHEIT, Herausgegeben von Hans Jochen Margull, Stuttgart 1961, bl. 30. 
staatsbestel nie. Die kerk (teoloë) moet nie eindeloos voortgaan met twis en stryd nie, maar saamkom om die saak openlik met mekaar te bespreek en tot konsensus van opinie te kom. Watter bybedoelings Konstantyn ook mag gehad het, een ding is seker, sonder sy inisiatief sou ons waarskynlik nie 'n Nicaenum gehad het nie. Maar hierdie keiserlike sinode het vir ons nog 'n boodskap. Die kerkvaders het hulle nie deur die keiser op 'n syspoor laat bring nie. Vir hom het dit gegaan om die vrede en die eenheid van die ryk, vir hulle het dit gegaan om die waarheid van die evangelie. Eers as hierdie waarheid buite enige twyfel gestel is, kan dit die saak werklik dien waarvoor Konstantyn die sinode saamgeroep het. Laat die kerk nooit vergeet nie dat die waarheid van die evangelie sy eintlike taak is, $\mathrm{nl}$. dit na te vors en in elke tyd suiwer te verwoord en te verkondig.

Na hierdie ekskurs kan ons nou terugkom na die saak waarom dit wesenlik gegaan het in Nicea. Ons het reeds gemeld dat dit gegaan het om die vraag na die verhouding tussen die Seun en die Vader en om die stryd te besleg wat ontstaan het as gevolg van die leer wat Arius in hierdie verband verkondig het. Nou is dit geensins my bedoeling om $u$ te vermoei met 'n uiteensetting van die hele Ariaanse stryd en alles wat daarmee saamhang nie. Ons het in die afgelope jare heelwat te doen gehad met sommige van die kernpunte van die Arianisme. Ter verfrissing van die geheue kan ek u verwys na die notule van die Geysersaak, na die proefskrif van $G$. $M$. $M$. Pelser en na 'n uitvoerige artikel van B. J. Engelbrecht in H.T.S. (1962) met 'n uitputtende menigte van woorde en begrippe in Grieks en Latyn wat in hierdie saak relevant is. In plaas van 'n oorsig van die stryd wil ek kortliks 'n aanduiding probeer gee van die Grieks-filosofiese denkstruktuur waaruit die Arianisme voortgekom het. ${ }^{5}$ )

Teenoor die bybelse geloofswysheid wat gegrond is in die openbaring as Godbepaalde gebeurtenis, gaan dit in die Griekse wysheid om die syn, en veral om die ewige, metafisiese ordening van die syn. Die Grieke het wel ook van openbaring gepraat, maar dan as 'n onmiddellike deelkry aan die waarheid. So is die wysheid van 'n Plato bv. ook verklaar. Hierdie waarheid staan egter heeltemal los van enige gebeurlikheid en is direk op die syn, of beter, op die oorsprong van die syn gerig. Die oorsprong van die syn, wat dieselfde is as die grond van die syn, is dan ook die sin van die syn, en dié word deur die Platonici ook "God" genoem. Hy, die oorsprong of grond van die syn, orden die materie sodat daar kosmos (ordening) ontstaan. Die Platoniese ideë word dan ook gedagtes van God genoem, sodat 'n mens deur die ideë by God uitkom. Die laaste grond van die syn, God self dus, is vir die mens

5) Georg Kretshmar, a.w., bl. 38-41. 
egter onverstaanbaar en kan nie in woorde uitgespreek word nie. Volgens hierdie ontologiese denkskema kan God nie skepper van die wêreld wees nie, want anders sou hy kenbaar wees. Daarom maak hy van 'n werktuig gebruik, nl. die "noes", die rasionele synsgrond teenoor God, die bo-rasionele grond. Dis by hierdie gedagte van die "Noes" as werktuig dat die teologie in die tweede eeu aangesluit het toe daar gepoog is om in die Grieks-filosofiese denkskema uitdrukking te gee aan die verhouding tussen God en Christus. As brug het gedien die Nuwe Testament uitsprake oor Christus as skeppingsmiddelaar (Kol. 1:16) Justinus was die eerste wat in die plek van die Griekse ,noes" die Logos van Johannes gestel het. Hierdie Logos het vlees geword in Christus en word naas God vereer, volgens Justinus. Ontologies is Christus, die Logos wat vlees geword het, dus openbaring van die grond van die wêreld, want $\mathrm{Hy}$ is die werktuig waardeur die grond van die syn die syn orden tot kosmos. Volgens die Bybelse getuienis het God egter die wêreld geskape, en nie slegs die materie georden nie. Daarom moet ook aanvaar word dat die wêreld ' $n$ tydelike begin gehad het. As Christus volgens hierdie ontologiese denke openbaring van God is in sy skeppingsmiddelaarsfunksie, dan staan hy nie net in betrekking tot God nie maar ook tot iets wat teenoor God staan, die wêreld. As die wêreld egter 'n tydelike begin gehad het, was daar 'n tyd dat hy nog nie was nie, en dan moet dit ook van Christus geld. Die noodwendige konsekwensie van hierdie redenering is dat $\mathrm{Hy}$ onder God gestel moet word, 'n skepsel soos die engele of mense, al oortref Hy hulle ook almal. Dit is die beskouing wat Arius ook gehuldig het en waaruit die Ariaanse stryd gespruit het.

Die wesenlike sake waarom dit in die Arianisme gaan, blyk duidelik uit ' $n$ brief van Arius aan Eusebius, biskop van Nicomedia. ${ }^{6}$ ) Hy kla in hierdie brief oor die vervolging wat hy en ander moet verduur van biskop Alexander wat verkondig: God altyd, die Seun Altyd, tegelyk die Vader, tegelyk die Seun. Die Seun koëksisteer met die ongebore God. Hy is immer-gebore. Nog in denke, nog in tyd is God voor die Seun. God altyd, Seun altyd, die Seun bestaan van God self.

In dieselfde brief deel hy ook kortliks aan Eusebius mee wat hy altyd verkondig het:

dat die Seun nie ongebore is nie, dat Hy nie deel is van die ongeborene op enige wyse nie en nie kom van enige substansie nie. Deur sy eie wil en raad het $\mathrm{Hy}$ bestaan voor die tyd, ten volle God, enig-gebore, onveranderlik. Voordat $\mathrm{Hy}$ gebore, of geskape, of aangestel of ingestel is, het $\mathrm{Hy}$ nie bestaan nie want $\mathrm{Hy}$ was nie ongebore nie.

6) Henry Bettenson, a.w., bl. 55. 
Hy en sy volgelinge, sê hy, word vervolg omdat hy sê dat die Seun ' $n$ begin gehad het, maar dat God sonder begin is. Hy word vervolg omdat hy sê die Seun is van wat nie is nie (ex ouk ontōn). Die konsilie van Nicea het in ' $n$ brief aan die bisdom van Alexandrieë waarin meegedeel word dat al die uitsprake van Arius veroordeel is, dan ook spesifiek hierdie twee sake genoem, nl. dat die Seun van God is van wat nie is nie, en dat daar' $n$ tyd was dat Hy nie was nie.

Die geloofsbelydenis van Nicea is dan ook hoofsaaklik gerig teen die christologiese dwaalleer van Arius. Ons glo $\ldots{ }^{7}$ ) in een Heer, Jesus Christus, die Seun van God, gebore uit die Vader, enig-gebore, d.w.s. van die substansie van die Vader, God uit God, Lig uit Lig, ware God uit ware God, gebore, nie gemaak nie, eenswesens met die Vader, deur wie alle dinge gemaak is in die hemel en op die aarde; wat vir ons, mense, en vir ons redding neergekom het en vlees gemaak is en ' $n$ mens geword het, gely het en op die derde dag opgestaan het, opgevaar het na die hemel en wat sal kom om lewendes en dodes te oordeel; en in die Heilige Gees.

Die Niceanum, soos wat ons hom in die Kerkboek het, is eers in 381 op die konsilie van Konstantinopel gefinaliseer. Op Nicea is slegs die eerste twee artikels vasgestel, waarvan die tweede soos hierbo opgeneem, die belangrikste was en wat teruggaan op 'n doopbelydenis wat deur Eusebius van Caesarea as konsep aan die vergadering voorgelê is. Dink ' $n$ mens aan Nicea, dink jy tegelyk aan hierdie tweede artikel wat die hart van die hele belydenis vorm, terwyl in een enkele woord, nl. "homo-ousios", die eintlike dogmatiese resultaat van die hele besinning uitgedruk is. In hierdie formulering het die opvatting van veral Athanasius geseëvier, die diaken uit Alexandrieë, wat geen lid van die konsilie was nie, maar slegs raadgewer van sy biskop en tewens geestelike leier van die kleinere, maar gewigtige regse groep op die konsilie.

As ter afsluiting enkele verdere opmerkings oor die boodskap van Nicea gemaak moet word, kan dit miskien die beste geskied deur die aandag op twee sake te vestig:

* Nicea leer ons dat die Bybelse evangelieboodskap nie sonder geweldpleging van sy essensiële inhoud in die ontologiese denksisteem van die Griekse filosofie geforseer kan word, soos Arius dit wou doen nie. Omdat dit in die hart van die evangelie om ' $n$ lewende persoon gaan, kan en wil hy nou eenmaal nie inpas in ' $n$ ontologiese sisteem, of in enige ander sisteem van logiese denke nie. Nicea leer ons dat teologie nie dieselfde as ontologie is nie, dat die syn van die filosofie as grond van alles,

7) H. Bettenson, a.w., bl. 35. 
nie dieselfde is as die Skepper-God van die Bybel nie. Nicea bring ons derhalwe in waarskuwende boodskap. En as daar nog enige twyfel bestaan oor die erns van hierdie waarskuwing, kan daar gerus gekyk word na die beste voorbeeld van 'n entspoorde ontologiese teologie soos ons dit aantref "by die Rooms-Katolisisme. Soos die geval met Arius was, so het ook by Rome die Christologie in die gedrang gekom deur sy ontologiese denksisteem. Die sprekende persoon van Christus teenoor die kerk is omvorm in 'n genademag in die kerk wat deur die kerk geabsorbeer is en wat nou verder gedistribueer word deur die kanale van die sakramente as 'n helende medikament. $\mathrm{Om}$ in te pas in die ontologiese denkskema moes die vrye sprekende Christus verander word in 'n hanteerbare genadekrag, maar daarmee het $\mathrm{Hy}$ ook sy vryheid verloor en 'n gevangene van die kerk geword. Ook in sy verlossingsleer oorheers die ontologiese kategorieë by Rome. 'n Mens word nie geregverdig deur die vryspraak van God nie, maar deur eie verdienste, omdat die syn van die mens herstel word deur die ingegiete genesende genadekrag, waardeur hy die vermoë verwerf om selfstandig voortgang in heiligheid te maak. Genade word ' $\mathrm{k}$ krag wat die mens onafhanklik van genade maak. Sonder om daarop uit te brei, is dit tog 'n behartenswaardige woord van Barth as hy beweer dat alle piëtistiese aktiwiteite 'n uiting van die grondgedagte van Rome op Protestantse vlak is.

** Die eintlike, allerbelangrikste boodskap van Nicea moet egter in die christologiese swaartepunt van artikel twee gesoek word. Hier is ons by die hart van die belydenis van Nicea. As hier vasgestel word dat die Seun .,ek tēs OUSIAS tou patros“" is, word daarmee uitgedruk dat $\mathrm{Hy}$ van die diepste wese van die Vader is en dat Hy onskeidbaar een met die Vader is. En as hier vasgestel word dat die Seun "homoousion tō patri" is, word daarmee uitgedruk dat $\mathrm{Hy}$ een wese met die Vader deel, onderskeie in bestaan en tog wesenlik een. Dat die Godheid van Christus, sy eenswesenheid met die Vader, op Nicea buite alle twyfel vasgestel is, het meer as net teologiese betekenis. Dit het veral soteriologiese betekenis. Nicea het hierdie aspek beklemtoon met die woorde:

wat vir ons, mense, en vir ons redding neergekom het... en 'n mens geword het.

Dit is wel so dat die verskillende loci van die teologie met mekaar vervleg is soos die drade van 'n spinneweb en dat die geheel in beweging kom as een draad aangeroer word. In die teologie beklee die christologie egter die beherende middelpunt en as dit daar verkeerd gaan, word dit voortgeplant langs die 
hele linie van loci. Wanneer daar 'n misvatting van die christologie plaasvind, het dit egter nie slegs 'n teologiese vergissing tot gevolg nie, maar 'n soteriologiese ramp. Sonder die belydenis van Nicea sou ons geloof vergeefs gewees het, sou ons nog in die sonde gelê het, sou die dood nog oor ons geheers het. Sonder Nicea sou die kerk slegs die gestalte van rog 'n godsdiens in die wêreld gewees het waarin dit uiteindelik gaan om selfregverdiging, selfredding, selfheiliging. Daarom is ons dankbaar vir Nicea, vir sy boodskap, en wil ons die himniese tweede artikel sing: God uit God, Lig uit Lig, ter wille van ons redding ' $n$ mens geword. 